\title{
Investing your money - what does the future hold?
}

\author{
Martin Lawrence, Director of Investments at Wesleyan, discusses the impact of Brexit and the \\ pandemic on the markets and what that means for 2021 and beyond.
}

As many people look to increase their financial stability in the wake of COVID-19, some may be considering investments as a path to help achieve this. However, as the world continues navigating through the pandemic, you might have questions around how to invest wisely during such unpredictable times, especially as the pandemic continues to impact global economies and stock markets.

As long-term investors, our investments team are focused on achieving strong fund performance over several years, expertly navigating the markets and any events that shape them.

\section{The effect of the pandemic}

Of course, the significant event of 2020 is the pandemic. At the start of 2020, markets barely reacted to COVID-19 as no one initially realised how serious and significant the virus was. When the world realised the severity of COVID-19, markets pivoted almost immediately. I have worked in investments for many years and have seen markets fall before, but the difference this time was the speed at which they fell.

From the middle of February to the middle of March 2020, the UK stock market was down by more than $30 \%$. By the end of the year, it was down by about $10 \%$, whereas some of the overseas markets were up about $15 \%$. One of the reasons the UK market fell harder than those in the US, Asia or Europe, is due to its composition, which is weighted towards the oil, travel and leisure, and financial services sectors, all of which have been hit hard during the pandemic.

In comparison, the US stock market is more weighted towards technology and healthcare. Both sectors did well, and taking technology as an example it's easy to see why - more people were buying laptops for home schooling, working from home, and purchasing new on-demand TV subscriptions to keep them entertained during lockdowns.

\section{Brexit and Biden}

At the end of 2020, a Brexit deal was agreed - an outcome that markets had expected and already priced in.

Shortly before Brexit, it became clear that Joe Biden would become the next US President. With a small majority in the House of Representatives, and only just securing the Senate, markets viewed this development favourably, confident that a Biden administration will have enough checks and balances in place to ensure the White House doesn't move too far in one direction in undoing Trump's policies towards China, trade and the environment, among others.

\section{Quiet optimism for 2021}

This positive tailwind that we have coming into 2021 is something to be aware of when it comes to planning or changing your investments.

As I mentioned earlier, at Wesleyan we have a long-term investment strategy. We are still in the midst of a public health crisis and an incredibly difficult time that can't be trivialised, but investment markets are always looking forwards.

The markets are acknowledging that we have the vaccine and that lockdowns are seemingly starting to have an impact. The UK and US are starting to make reasonable progress and economic data is starting to look a little better.

If you add this to the other factors mentioned above, such as the calmer American political backdrop, we expect a more positive picture for markets than what we saw for most of 2020, which should lead to stronger financial returns.

\section{Looking further ahead}

If we start to look further ahead there are two asset classes that stand out as the ones that are going to make returns longer term: equities and property.

That's because, for equities, we will have dividends making a return at some point which will have a compound effect on the good back story I've talked about so far.

For property, while retail is struggling at the moment, shops will reopen, or they will be used for different purposes. We have seen the commercial property market constantly reinventing itself in the past and it's likely that trend will continue.

If you're looking ahead, ten or 20 years, I am confident that the markets should be able to produce some good returns. Of course, with investments there are never any guarantees, and that's something to always be mindful of [Keep in mind that investment values can go down as well as up, so you could get back less than you invest].

Markets are not appropriate for everybody, and it is often worth talking to a specialist, such as a Wesleyan Financial Services Consultant, who can help to make sure that you're suitably matched to what is appropriate for your situation.

If you're considering your investments or looking to invest, you can book a 30-minute quick start no-obligation chat with a Wesleyan Financial Services Consultant by visiting: https://bit.ly/2YMzcbz. Alternatively, call: 08003163784.

\section{About Martin Lawrence (ASIP)}

Martin joined Wesleyan in 1995 as an Investment Analyst, after graduating from the University of Exeter with a degree in Mathematics, and he subsequently qualified as an Associate of the Chartered Financial Analyst (CFA) Society of the UK. He became a Fund Manager in 2001. For 20 years, he managed several Wesleyan funds, including its multi-asset With Profits Fund, which he managed until the end of December 2020. As Director of Investments at Wesleyan, Martin is responsible for overseeing the management of Wesleyan's funds and award-winning in-house Investments team, including our Fund and Property Managers and Analysts. Martin is also a Director of Wesleyan Unit Trust Managers Ltd. 